\title{
ISOLATION AND PURIFICATION OF POLYSACCHARIDES FROM LITCHI SEEDS, WITH AN ANALYSIS OF IN VITRO HYPOGLYCEMIC EFFECT
}

\author{
Y.K. PAN*, Y.H. HAN* and R.Q. HUANG** \\ School of Life Sciences, South China Normal University, Guangzhou 510631, PR China
}

(Received: 20 December 2019; accepted: 11 June 2020)

\begin{abstract}
Polysaccharides from litchi (Litchi chinensis) seeds were isolated and purified using ion exchange column chromatography. Molecular weight distribution of polysaccharides and monosaccharides were detected. Preliminary structural characterisation of polysaccharides was conducted using infrared, nuclear magnetic, and other spectroscopy techniques in combination with methylation analysis. In vitro cell culture experiments were designed to detect the effects of polysaccharides on cell growth and cellular glucose consumption. We extracted and analysed three polysaccharides from litchi seed. Monosaccharide composition and infrared spectroscopy detection showed that the skeleton structure of polysaccharides consisted of glucose and mannose. Polysaccharides 1 and 2 are similar and have relatively high glucose content (around 70\%); polysaccharide 3 has $39.17 \%$ glucose only but is rich in arabinose (about $21.03 \%)$. In a certain range of use $\left(50 \sim 1000 \mu \mathrm{g} \mathrm{ml}^{-1}\right)$, polysaccharides 1 and 2 have no significant impacts on cell growth, while polysaccharide 3 can promote proliferation to some extent. All three polysaccharides can promote in vitro cellular glucose consumption, especially polysaccharide 3, which shows the strongest promotion, a significant dose effect, and synergistic effect with insulin. The above results highlight important roles of litchi seed polysaccharides in promoting cell growth and validate litchi seed polysaccharides as potential drugs for hypoglycaemia.
\end{abstract}

Keywords: litchi seed, polysaccharide, in vitro cell experiment, hypoglycaemic effect

As a member of the family Sapindaceae, Litchi chinensis Sonn. is one of the high-yielding fruits in China. It is sweet, juicy, and popular among consumers. Processing of litchi generates agricultural waste, which up to now has been discarded (ZHU et al., 2019). However, litchi seeds are used in traditional Chinese medicine for exhausting qi, dispelling cold, and relieving pain. Research reports indicate that litchi seeds have anti-inflammatory (QI et al., 2015), antitumour (CHUNG et al., 2017), anti-oxidation (WANG et al., 2011), and other pharmacological activities. Their chemical components mainly consist of flavonoids (WU et al., 2019), tannins (Luo et al., 2009), terpenes (Luo et al., 2009), etc. Polysaccharides are also among the important functional substances in litchi seeds. Studies associated with polysaccharides of litchi seeds are only limited to extraction (STUART \& BUIST, 2010) and antioxidant (ChEn et al., 2011) and antibacterial activities (QI et al., 2015) of crude polysaccharides. And in the field of exploiting new diabetes drugs in recent years, the hypoglycaemic activities of plant polysaccharides are always a research hotspot (Popov et al., 2014).

In this study, crude polysaccharides extracted from litchi seeds were isolated and purified. Monosaccharide compositions and in vitro hypoglycaemic effects of 3 polysaccharides were analysed. This study provides experimental evidences for the exploitation and utilisation of litchi seeds as a new hypoglycaemic drug.

\footnotetext{
* Y.K. Pan and Y.H. Han contributed equally to the work

** To whom correspondence should be addressed.

Phone: +86 20 13925120692; fax: +86 20 85211372; e-mail: qiangdoctor@126.com
} 


\section{Materials and methods}

\subsection{Materials and reagents}

Mature seeds of the plant Litchi chinensis (Sapindaceae) were identified by Guangdong Academy of Agricultural Sciences. Cell strain: human hepatoma Cell HepG2 was obtained from Guangzhou Editgene Technology Co., Ltd. DEAE-Sepharose fast flow anion exchange chromatography resin, American GE, and Glucose kit, Shanghai Runcheng Biotechnology Co., Ltd., were used in the experiments.

\subsection{Experimental methods}

1.2.1. Extraction and purification of litchi seed polysaccharides.

Dried litchi seeds were crushed into powder, the screened powder was evenly mixed with water $\left(60^{\circ} \mathrm{C}\right)$ at a ratio of $1: 10\left(\mathrm{~g} \mathrm{ml}^{-1}\right)$. Ultrasonic extraction was performed for 3 times $(20$ $\min$ ) and the solution was concentrated under reduced pressure. Four times ethanol of $95 \%$ was added to the concentrated solution. After the deproteinisation treatment by $\mathrm{H}_{2} \mathrm{O}_{2}$, decolourisation method (YANG et al., 2016), and Sevag method (Hu et al., 2011), DEAESepharose fast flow ion exchange column chromatography (IEC) was used for separation and purification (DuBoIs et al., 1956). Three polysaccharides were obtained by collecting the same peak position, dialysis, concentration, and freeze-drying.

1.2.2. Detection of molecular weight distribution. Gel permeation chromatography (GPC) was adopted to detect the molecular weight (Hu et al., 2011) using Waters 2410 differential refraction detector. A series of dextran solutions with different molecular weights were prepared as standards. The molecular weight of the sample was calculated according to the corresponding elution volume.

1.2.3. Detection of monosaccharide composition. Polysaccharides were hydrolysed with $4 \mathrm{M}$ trifluoroacetic acid (TFA, $5 \mathrm{ml}$ ) in sealed tube at $100{ }^{\circ} \mathrm{C}$ for $2 \mathrm{~h}$. The excess acid was evaporated in a water bath at $40{ }^{\circ} \mathrm{C}$; upon the completion of hydrolysis, it was codistilled with MeOH. HPAEC-PAD method was used to determine monosaccharide content. HPAEC-PAD on the Dionex ICS-2500 system was used for the analysis of hydrolysates by ion chromatography (LEHRFELD et al., 1985). Standard ribose, rhamnose, arabinose, xylose, mannose, glucose, and galactose were used as standards, and treated and detected by the above steps.

1.2.4. Infrared spectrum detection. Two micrograms of polysaccharide sample was weighed, evenly mixed, and ground with dried potassium bromide in a mortar. The mixture was then pressed into a sheet by a tableting machine and scanned with Fourier transform infrared spectrometer in the wavelength range of $400-4000 \mathrm{~cm}^{-1}$ (YUAN et al., 2010).

1.2.5. Methylation analysis. The three polysaccharide samples were treated with $90 \%$ formic acid $(3 \mathrm{ml})$ in sealed tubes at $100{ }^{\circ} \mathrm{C}$ for $10 \mathrm{~h}$ (HAKomori, 1964). Upon the removal of formic acid, $4 \mathrm{M}$ TFA was used for heating under the above-mentioned conditions. The hydrolysates were condensed to dry state. The acetylation product samples were determined by Shimadzu GCMS-QP 2010 gas chromatography-mass spectrometry with a constant volume of $10 \mathrm{ml}$. 
1.2.6. Nuclear magnetic analysis. $50 \mathrm{mg}$ sample was accurately weighted and dissolved in $500 \mu \mathrm{l}$ deuterium substitute water, then transferred to the nuclear magnetic tube for spectral measurement.

1.2.7. In vitro cytotoxicity and glucose consumption analysis. Three polysaccharides were prepared in different concentrations, 50, 100, 250, 500, 750, and $1000 \mu \mathrm{g} \mathrm{ml}^{-1}$, with 5 $\mu \mathrm{g} \mathrm{ml}^{-1}$ rosiglitazone, a commonly used hypoglycaemic drug, as a positive control for treatment of cells for $24 \mathrm{~h}$ (no insulin treatment and insulin treatment). Glucose concentration and cell activity were determined by glucose kit (glucose oxidase method) and methylene blue method (FeLICE et al., 2009).

\subsection{Data processing}

The software Origin 9.0 was used to draw the curve of ion exchange chromatography gradient elution and SPSS 19.0 was used for statistical analysis of in vitro cell experiment results. The results were expressed as mean \pm standard deviation (SD).

\section{Results and discussion}

\subsection{Purification of polysaccharides}

As shown in Figure 1, three polysaccharides were mainly obtained by DEAE-Sepharose fast flow IEC in the $0,0.1,0.2$, and $0.3 \mathrm{~mol}^{-1} \mathrm{NaCl}$ elution sections, and were named polysaccharide 1 , polysaccharide 2 , and polysaccharide 3 , respectively. Polysaccharide 1 was eluted with pure water, and is a neutral polysaccharide. Polysaccharide 2 and 3 are weak acidic polysaccharides (WANG et al., 2017).

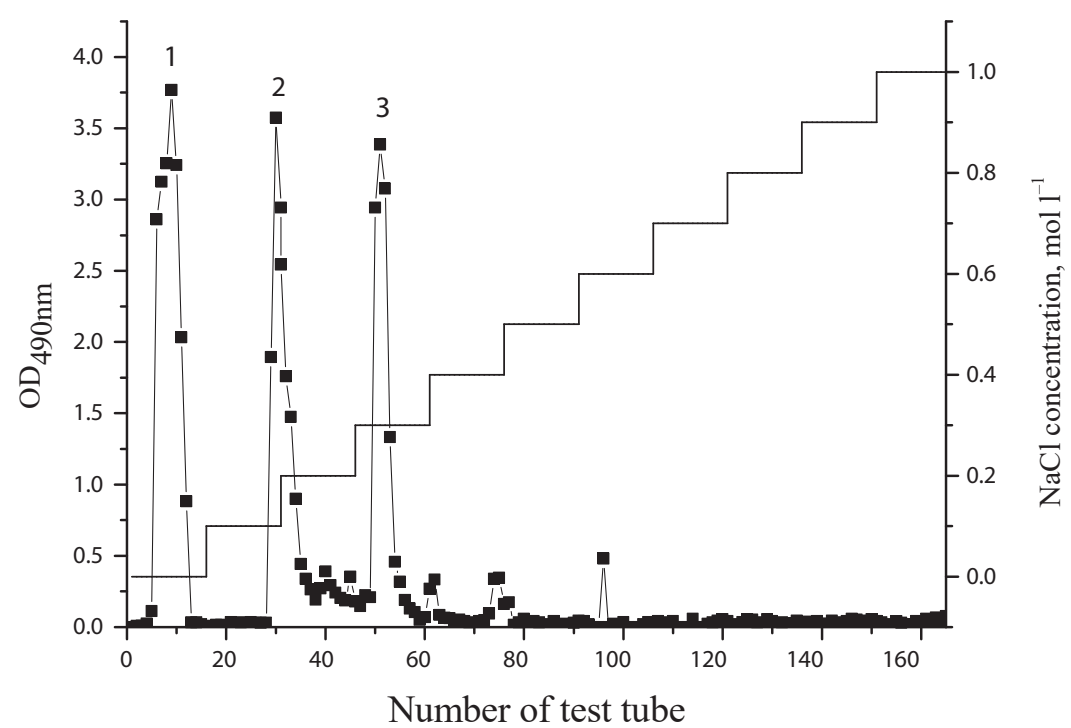

Fig.1. Gradient elution curve for litchi seed polysaccharides obtained by IEC 


\subsection{Molecular weight of purified polysaccharides}

The results indicate that molecular weights of polysaccharides 1 and 3 are nearly equal, and are slightly higher than that of polysaccharide 2 . The molecular weight dispersion coefficients $(\mathrm{Mw} / \mathrm{Mn})$ of the three polysaccharides are all close to 1, indicating that the molecular weight distribution is narrow and the molecular weight homogeneity is good (Table 1).

Table 1. Results of molecular weight distribution of purified polysaccharides

\begin{tabular}{lccc}
\hline Component & $\begin{array}{c}\text { Number-average molecular } \\
\text { weight }(\mathrm{Mn})(\mathrm{Da})\end{array}$ & $\begin{array}{c}\text { Weight-average molecular } \\
\text { weight }(\mathrm{Mw})(\mathrm{Da})\end{array}$ & $\mathrm{Mw} / \mathrm{Mn}$ \\
\hline 1 & $5.93 \times 10^{4}$ & $7.19 \times 10^{4}$ & 1.21 \\
2 & $6.66 \times 10^{3}$ & $7.78 \times 10^{3}$ & 1.17 \\
3 & $6.64 \times 10^{4}$ & $7.46 \times 10^{4}$ & 1.12 \\
\hline
\end{tabular}

\subsection{Monosaccharide composition of purified polysaccharides}

Seven monosaccharides are listed in Table 2. The contrastive analysis showed that glucose content is the highest in polysaccharides 1,2, and 3 followed by mannose content. However, compared to polysaccharides 1 and 2, the glucose content in polysaccharide 3 is relatively low, but the contents of arabinose and galactose are both higher.

Table 2. Monosaccharide composition of purified polysaccharides

\begin{tabular}{lccccccc}
\hline Component & \multicolumn{9}{c}{ Mole percent (\%) } \\
& $\begin{array}{c}\text { Ribose } \\
(\mathrm{Rib})\end{array}$ & $\begin{array}{c}\text { Rhamnose } \\
(\text { Rha })\end{array}$ & $\begin{array}{c}\text { Arabinose } \\
(\text { Ara })\end{array}$ & $\begin{array}{c}\text { Xylose } \\
(\text { Xyl })\end{array}$ & $\begin{array}{c}\text { Mannose } \\
(\text { Man })\end{array}$ & $\begin{array}{c}\text { Glucose } \\
(\text { Glu })\end{array}$ & $\begin{array}{c}\text { Galactose } \\
(\text { Gal })\end{array}$ \\
\hline 1 & 0.25 & 0.68 & 1.72 & 0.08 & 21.71 & 73.04 & 2.52 \\
2 & 1.01 & 0.43 & 0.34 & 0.5 & 21.27 & 75.49 & 0.95 \\
3 & 0.67 & 0.79 & 21.03 & 0.99 & 23.88 & 39.17 & 13.47 \\
\hline
\end{tabular}

\subsection{Infrared spectrum detection of polysaccharides}

Infrared spectrum was used to detect the structural features of the three polysaccharides, including ring structure, hemiacetal hydroxyl structure and substituent type. The detection results of the three polysaccharides are shown in figure $2 \mathrm{~A}, 2 \mathrm{~B}$, and $2 \mathrm{C}$.

For polysaccharide 1, the telescopic vibration absorption peaks of -OH and $\mathrm{C}-\mathrm{H}$ groups occur at $3398 \mathrm{~cm}^{-1}$ and $2934 \mathrm{~cm}^{-1}$, respectively, the bending vibration absorption peak of -OH occurs at $1624 \mathrm{~cm}^{-1}$ and the deformation absorption peak of $=\mathrm{CH}_{2}$ at $1414 \mathrm{~cm}^{-1}$. The absorption peak of C-O appears at $1153 \mathrm{~cm}^{-1}$, and the characteristic absorption peak of C-O-C at $1080 \mathrm{~cm}^{-1}$ and $1024 \mathrm{~cm}^{-1}$, indicating that polysaccharide 1 is also in the form of pyranose. The characteristic absorption peak of $\alpha$-glycoside bond appearing at $849 \mathrm{~cm}^{-1}$ indicates that polysaccharide 1 has $\alpha$-glycoside bond (SHI et al., 2007) (Figure 2A).

In Figure 2B, the telescopic vibration absorption peak of -OH occurs at $3425 \mathrm{~cm}^{-1}$, the bending vibration absorption peak of $-\mathrm{OH}$ at $1615 \mathrm{~cm}^{-1}$, and the deformation absorption peak of $=\mathrm{CH}_{2}$ at $1405 \mathrm{~cm}^{-1}$. The absorption peak of C-O appears at $1141 \mathrm{~cm}^{-1}$, and the characteristic absorption peaks of C-O-C at $1098 \mathrm{~cm}^{-1}$ and $1023 \mathrm{~cm}^{-1}$, indicating that polysaccharide 2 is in the form of pyranose. 


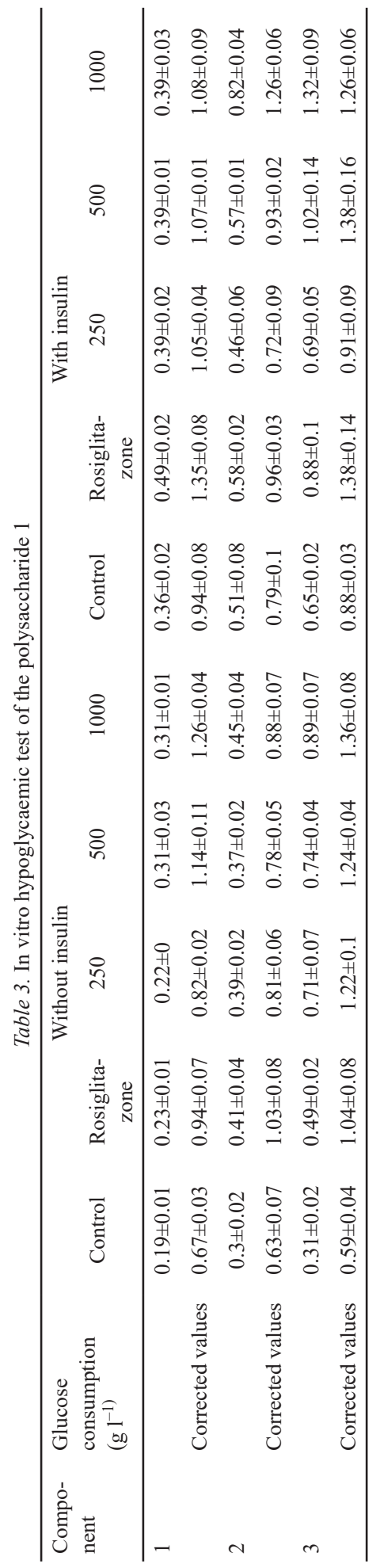


In Figure $2 \mathrm{C}$ for polysaccharide 3, the telescopic vibration absorption peak of -OH occurs at $3416 \mathrm{~cm}^{-1}$, the bending vibration absorption peak of $-\mathrm{OH}$ at $1608 \mathrm{~cm}^{-1}$, and the deformation absorption peak of $=\mathrm{CH}_{2}$ at $1409 \mathrm{~cm}^{-1}$. The characteristic absorption peak of $\mathrm{C}-\mathrm{O}-\mathrm{C}$ at $1096 \mathrm{~cm}^{-1}$ indicates that polysaccharide 3 is also in the form of pyranose.
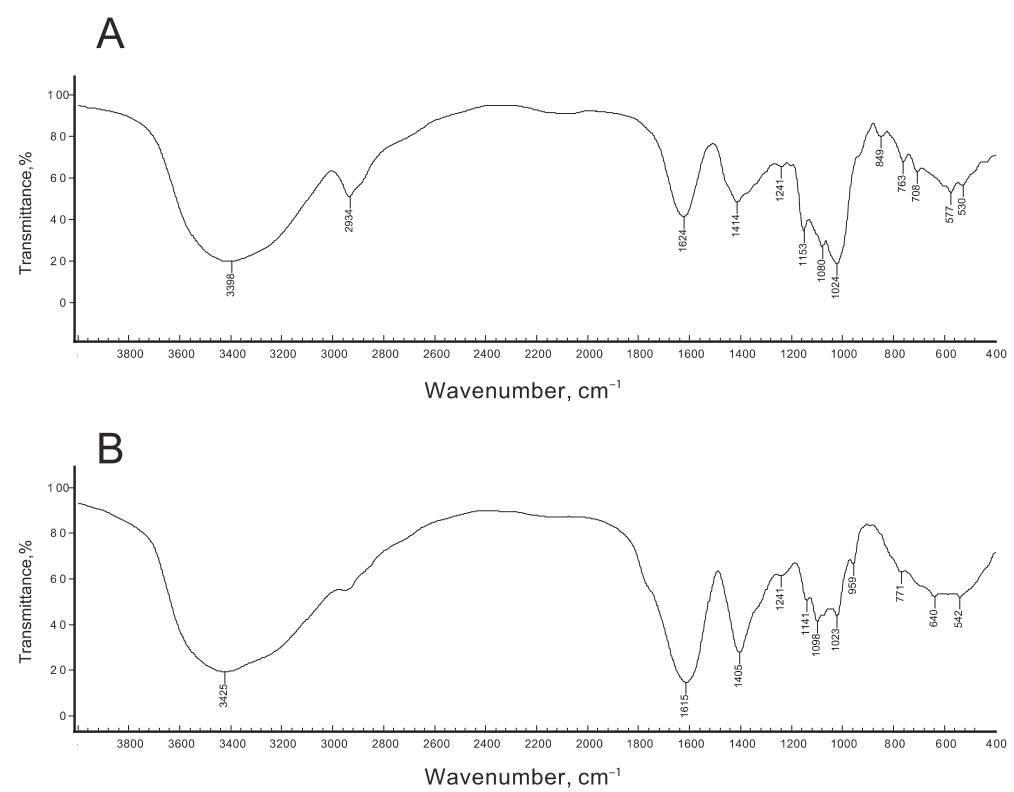

C

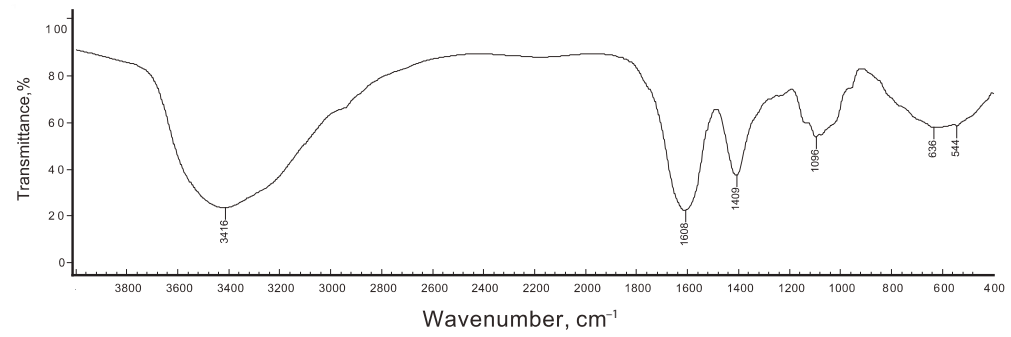

Fig. 2. Infrared spectrogram of polysaccharides from litchi seeds A: polysaccharide 1; B: polysaccharide 2; C: polysaccharide 3

\subsection{Methylation and nuclear magnetism}

As shown in Figure 3A, B, and C, the carbon spectrum analysis of polysaccharide 1, 2, and 3 at ${ }^{13} \mathrm{C}$ NMR $\left(126 \mathrm{MHz}, \mathrm{D}_{2} \mathrm{O}\right)$ indicates that the nuclear magnetic carbon spectrum signal is mainly concentrated in 60-120 PPM.

As shown in Figure 3A, the heterocarbon regions of major heterocarbon signal peaks $\delta 101,97$, and 93 are mainly concentrated in $\delta 93 \sim 110$. However, 78.95, 78.74, 78.16, 77.90, and 77.72 have already migrated to the low field. According to the results of methylation, the $\mathrm{C} 4$ of $00 . . \rightarrow 4)$-Glcp-( $1 \rightarrow$ or the $\mathrm{C} 3$ and $\mathrm{C} 4$ of Rha may also be the C4 of galactose (ZHU et al., 2013). 
As shown in Figure 3B, the heterocarbon region of major heterocarbon signal peak $\delta 101.92$ is mainly concentrated in $\delta 93 \sim 110$. However, $\delta 82.08,79.84,78.51,77.57$, and 77.17 have already migrated to the lower field, indicating the probable replacement of $\mathrm{C} 2,3$, and 4 .

As shown in Figure 3C, the heterocarbon regions of major heterocarbon signal peaks $\delta 100.89$ and 109.49 are mainly concentrated in $\delta 93 \sim 110 . \delta 79.91,79.85,79.47,79.08,78.52$, 78.16 , and 77.75 have already migrated to the lower field, indicating the replacement of glycoside bonds $\mathrm{C} 2, \mathrm{C} 3$, and $\mathrm{C} 4$. According to the results of methylation, it may be the $\mathrm{C} 3$ / $\mathrm{C} 4$ of $\rightarrow 3,4)$-Rhap-( $1 \rightarrow$, the $\mathrm{C} 4$ of $\rightarrow 4)$-Glcp-( $1 \rightarrow$, the $\mathrm{C} 3$ of $\rightarrow 3)$-Galp- $(1 \rightarrow$ and the $\mathrm{C} 3$ of $\rightarrow 3,6)-$ Galp- $(1 \rightarrow)$ (WEN et al., 2014).

A
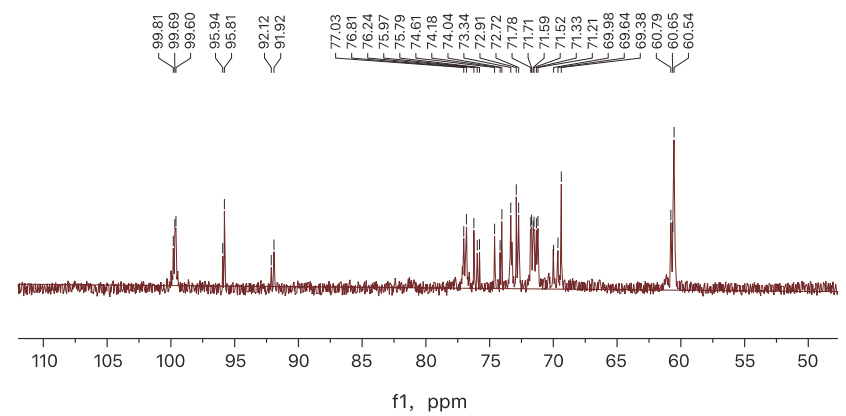

B
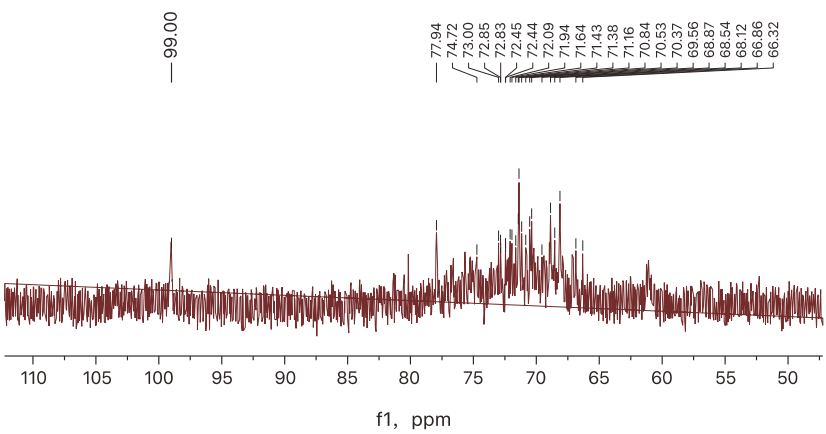

C

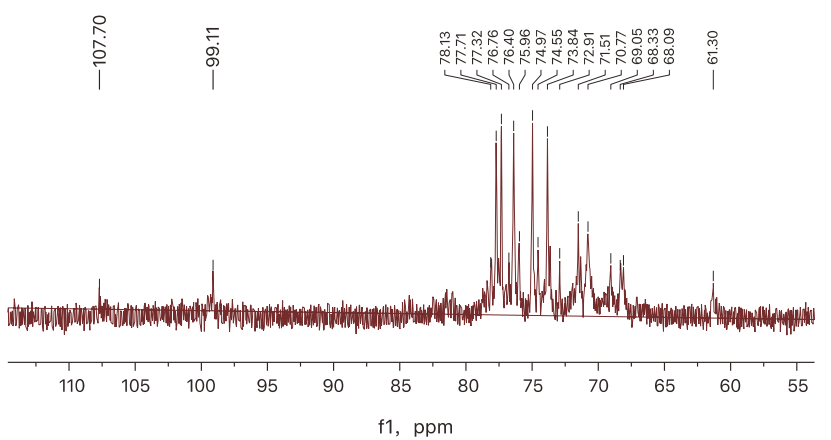

Fig. 3. Carbon spectrogram of polysaccharides

A: polysaccharide 1; B: polysaccharide 2; C: polysaccharide 3 


\subsection{Effects on cell growth}

As shown in Figure 4, polysaccharides 1 and 2 had no effect on cell growth, which maintained the activity at around $100 \%$; but for polysaccharide 3 , the pro-proliferation effect on cells was increasing with the increase of concentration, also this effect appeared at $250 \mu \mathrm{g} \mathrm{ml}^{-1}$ and even reached up to $151 \pm 3.1 \%$ at $1000 \mu \mathrm{g} \mathrm{m}^{-1}$. The result indicates that polysaccharides 1 and 2 have no effects on cell growth, while polysaccharide 3 has a growth promoting effect on cells.

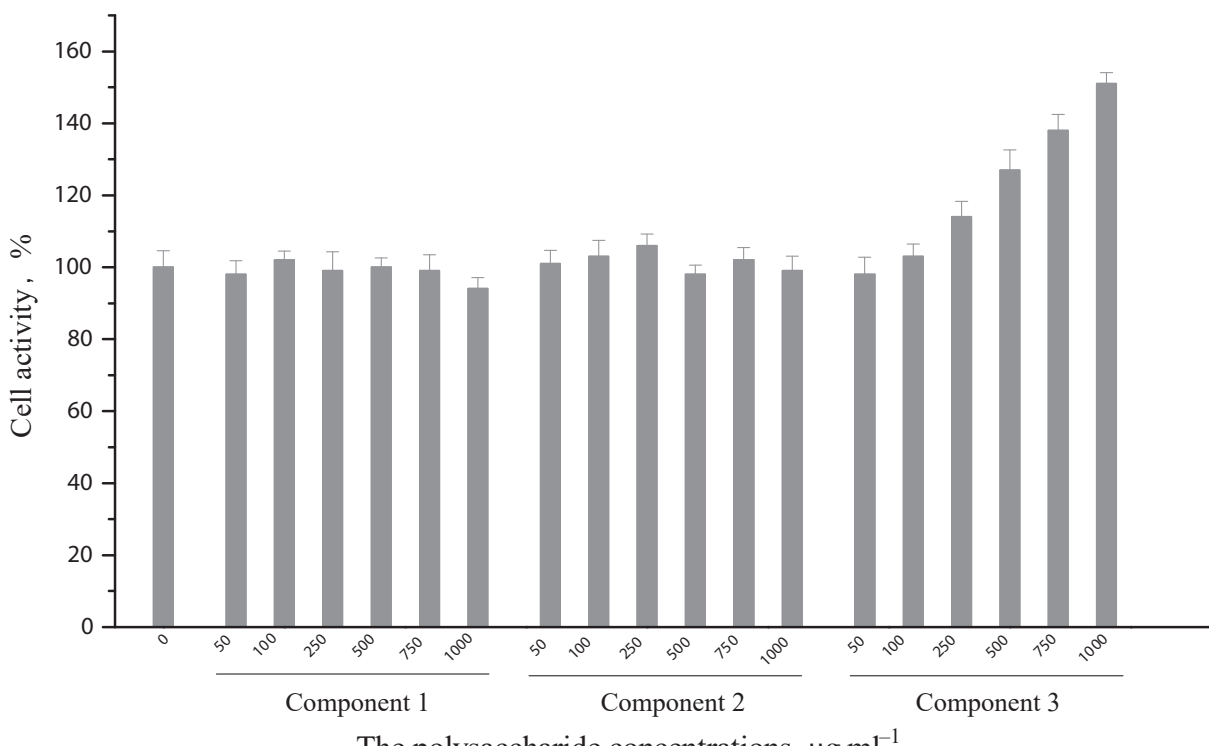

Fig. 4. Effects of three polysaccharides on cell activity

\subsection{Hypoglycemic test}

Under the treatment without insulin, polysaccharide 1 could effectively promote glucose consumption and showed dosage effect after activity correction. While having been treated by insulin, polysaccharide 1 showed no significant synergistic effect with insulin. Compared with rosiglitazone (a commonly used hypoglycaemic drug, $5 \mu \mathrm{g} \mathrm{ml}^{-1}$ and without insulin), the $500 \mu \mathrm{g} \mathrm{ml}^{-1}$ polysaccharide 1 had better effect on promoting cellular glucose consumption (Table 1).

Under the treatment without insulin, polysaccharide 2 could also promote glucose consumption, but the dosage effect was not significant. While having been treated by insulin, polysaccharide 2 had synergistic effect with insulin at high concentration. Compared with 5 $\mu \mathrm{g} \mathrm{ml}^{-1}$ rosiglitazone, with or without insulin, the cellular glucose consumption was higher than that of under treatment with $5 \mu \mathrm{g} \mathrm{ml}^{-1}$ rosiglitazone only at high concentration of the polysaccharide $2\left(1000 \mu \mathrm{g} \mathrm{ml}^{-1}\right)$.

At the lack of insulin, polysaccharide 3 can promote glucose consumption, and at high concentration the dosage effect is significant. While insulin treated, polysaccharide 3 and insulin have synergistic effect, which can promote glucose consumption and show significant 
dosage effect. Compared with $5 \mu \mathrm{g} \mathrm{ml}^{-1}$ rosiglitazone, with or without insulin, the cellular glucose consumption are higher than polysaccharide $3\left(250 \mu \mathrm{g} \mathrm{ml}^{-1}\right)$ at low concentration, indicating that the $250 \mu \mathrm{g} \mathrm{ml}^{-1}$ polysaccharide 3 had better effect of promoting cellular glucose consumption than the $5 \mu \mathrm{g} \mathrm{ml}^{-1}$ rosiglitazone.

\section{Conclusions}

In this study, a total of 3 polysaccharides from litchi seeds were isolated and purified using the decolourisation and deproteinisation methods. The effects on cell growth and hypoglycaemic activity of each polysaccharide were detected based on in vitro cell experiments. The results showed that polysaccharides 1 and 2 have no distinct effect on cell growth, while polysaccharide 3 has some pro-proliferation effect with the increase of polysaccharide concentration, and below $1000 \mu \mathrm{g} \mathrm{ml}^{-1}$ the cell activity can reach up to $151 \pm 3.1 \%$. In addition, all three polysaccharides can promote the effect of glucose consumption. Compared with $5 \mu \mathrm{g} \mathrm{ml}^{-1}$ rosiglitazone, $500 \mu \mathrm{g} \mathrm{ml}^{-1}$ polysaccharide $1,1000 \mu \mathrm{g}$ $\mathrm{ml}^{-1}$ polysaccharide 2 , and $250 \mu \mathrm{g} \mathrm{ml}^{-1}$ polysaccharide 3 promote cellular glucose consumption better, especially the $250 \mu \mathrm{g} \mathrm{ml}^{-1}$ polysaccharide 3 , which also has significant dosage effect and synergistic effect with insulin.

Experimental results indicated that, in the same plant, the polysaccharides with different monosaccharides had quite different effects on cell growth and metabolism. Therefore, the selective acquisition of phytochemicals and the exploiting and utilisation of plant polysaccharides as new hypoglycaemic drugs have great research prospects. In the next study, we intend to use selected diabetes model mice to explore the effects of the polysaccharide 3 on blood glucose, superoxide dismutase (SOD), malondialdehyde (MDA), and liver glycogen in diabetic mice, and to continue the study on the in vivo hypoglycaemic effect and mechanism of polysaccharides from litchi seeds.

The research was supported by Guangzhou Science and Technology Program key projects (201707010372); Guangdong Forestry Science and Technology Innovation Project (2016KJCX008); and Zhanjiang City Science and Technology Development Special Fund Competitive Distribution Project 2018A01016.

\section{References}

Chen, Y.Y., LuO, H.Y. \& GaO, A.P. (2011): Ultrasound-assisted extraction of polysaccharides from litchi (Litchi chinensis Sonn.) seed by response surface methodology and their structural characteristics. Innov. Food Sci. Emerg., 12, 305-309.

Chung, Y.C., Chen, C.H., Tsai, Y.T., Lin, C.C., Chou, J.C., ... \& Hsu, C.P. (2017): Litchi seed extract inhibits epidermal growth factor receptor signaling and growth of two non-small cell lung carcinoma cells. $B M C$ Complem. Altern. Med., 17(1), 16.

Dubois, M., Gilles, K.A., Hamilton, J.K., Rebers, P.A. \& Smith, F. (1956): Colorimetric method for determination of sugars and related substances. Anal. Chem., 28, 350-356.

Felice, D.L., Sun, J. \& LiU, R.H. (2009): A modified methylene blue assay for accurate cell counting. J. Funct. Foods, 1, 109-118.

HAKOMORI, S. (1964): A rapid premethylation of glycolipid, and polysaccharide catalyzed by methylsulfinyl carbanion in dimethyl sulfoxide. J. Biochem., 55, 205-208. 
Hu, X.Q., Huang, Y.Y., Dong, Q.F., Song, L-Y., Yuan, F. \& Yu, R.M. (2011): Structure characterization and antioxidant activity of a novel polysaccharide isolated from pulp tissues of Litchi chinensis. J. Agr. Food Chem., 59, 11548-11552.

LeHrFeLD, J. (1985): Simultaneous gas-liquid chromatographic determination of aldonic acids and aldoses. Anal. Chem., 57, 346-348.

Luo, X., Yu, M.Y., JiAng, N., Xu, X.Y., Zeng, J. \& Zheng, L.Y. (2009): Effects of Auricularia polytricha polysaccharide on mouse macrophage cytokine and iNOS gene expression. Mycosystema, 28, 435-439.

Popov, S.V., Ovodova, R.G., Golovchenko, V.V., Khramova, D.S., Markov, P.A., ... \& Ovodov, Y.S. (2014): Pectic polysaccharides of the fresh plum Prunus domestica L. isolated with a simulated gastric fluid and their anti-inflammatory and antioxidant activities. Food Chem., 143, 106-113.

QI, S.J., Huang, H., Huang, J.Y., Wang, Q.Y. \& WeI, Q.Y. (2015): Lychee (Litchi chinensis Sonn.) seed water extract as potential antioxidant and anti-obese natural additive in meat products. Food Control, 50, 195-201.

ShI, Y., Sheng, J.C., YAng, F.M. \& Hu, Q.H. (2007): Purification and identification of polysaccharide derived from Chlorella pyrenoidosa. Food Chem., 103, 101-105.

StUART, L.J. \& BUIST, P.H. (2010): The absolute configuration of methyl dihydrosterculate: an unusual phyto-fatty acid isolated from the seed oil of Litchi chinensis. Tetrahedron-Asymmetr., 15, 401-403.

WANG, L.J., Lou, G.D., MA, Z.J. \& LIU, X.M. (2011): Chemical constituents with antioxidant activities from litchi (Litchi chinensis Sonn.) seeds. Food Chem., 126, 1081-1087.

WANG, M., YANG, X.B., ZhaO, J.W., Lu, C.J. \& ZHU, W. (2017): Structural characterization and macrophage immunomodulatory activity of a novel polysaccharide from Smilax glabra Roxb. Carbohyd. Polym., 156, 390-402.

Wen, L.R., Wu, D., Jiang, Y.M., Prasad, K.N., Lin, S., .. \& Yong, B. (2014): Identification of flavonoids in litchi (Litchi chinensis Sonn.) leaf and evaluation of anticancer activities. J. Funct. Foods, 6, 555-563.

Wu, J., Xu, Y., Liv, X., Chen, M., Zhu, B., .... \& WANG, S. (2019): Isolation and structural characterization of a non-competitive $\alpha$-glucosidase inhibitory polysaccharide from the seeds of Litchi chinensis Sonn. Int. J. Biol. Macromol., 154, 1105-1115.

YANG, B., Prasad, K.N. \& JiAnG, Y.M. (2016): Structure identification of a polysaccharide purified from litchi (Litchi chinensis Sonn.) pulp. Carbohyd. Polym., 137, 570-575.

Yuan, F., Yu, R.M., Yin, Y., Shen, J.R., Dong, Q.F... \& Song, L.Y. (2010): Structure characterization and antioxidant activity of a novel polysaccharide isolated from Ginkgo biloba. Int. J. Biol. Macromol., 46, 436439.

Zhu, Q.Q., JiAnG, Y.M., Lin, S., Wen, L.R., Wu, D., ... \& YANG, B. (2013): Structural identification of $(1 \rightarrow 6)$--d-glucan, a key responsible for the health benefits of longan, and evaluation of anticancer activity. Biomacromolecules, 14, 1999-2003.

Zhu, X.R., WAnG, H., Sun, J., YAng, B., Duan, X.W. \& Jiang, Y.M. (2019): Pericarp and seed of litchi and longan fruits: Constituent, extraction, bioactive activity, and potential utilization. J. Zhejiang Univ. Sc. B, 20, 503512. 